\title{
A quantitative electrophysiological study of acute idiopathic polyneuritis
}

\author{
A. MARTinez-Figueroa, S. HANSEN, AND J. P. BALlantyne \\ From the University Department of Neurology, Institute of Neurological Sciences, \\ Southern General Hospital, Glasgow
}

SUMMARY The motor unit content and the dimensions of individual motor unit action potentials were studied in 17 patients with acute idiopathic polyneuritis from one week to $9 \frac{1}{2}$ years after the onset of the illness. An initial decrease in motor unit numbers is followed by a progressive increase with the passage of time from the onset of the illness. The latencies, areas, amplitudes, and durations of individual motor unit potentials were increased above normal values. The results suggest the presence of significant axonal damage in the majority of cases of acute idiopathic polyneuritis. The intramuscular nerve fibres are the site cf most severe electrophysiological dysfunction in this study.

The syndrome of acute idiopathic polyneuritis has been delineated as a well-defined entity, despite an unpredictable rate of onset, a wide spectrum of clinical manifestations, and a variable prognosis. The aetiology and pathogenesis of this condition have not been clearly elucidated, while the pathological correlates of the clinical events are poorly understood (Sigwald and Nouailhat, 1970).

An extensive literature on this condition has yielded largely qualitative information on the pathological concomitants of the disease (Peterman et al., 1959; Bannister and Sears, 1962; Humphrey, 1964; Isch et al., 1964; Lambert and Mulder, 1964; Bergamini et al., 1966; McQuillen, 1971; Kimura and Butzer, 1975; McLeod et al., 1976; Raman and Taori, 1976). The introduction of quantitative methods of electromyography (McComas et al., 1971; Ballantyne and Hansen, 1974a, b) has contributed new information on the neurophysiological changes in a number of neuromyopathies (Ballantyne and Hansen, 1974a, b, 1975). The purpose of the present paper is to report the results of the application of these techniques-namely, the estimation of the number of motor units in the extensor digitorum brevis (EDB) muscle, together with the quantification of the changes in the electrophysiological parameters of these motor units and to analyse these changes in terms of the underlying pathophysiological processes and evolution of the clinical syndrome.

Accepted 14 October 1976

\section{Methods}

The numbers of motor units in the EDB muscles of these patients were estimated by a technique described by Ballantyne and Hansen (1974a). The amplitudes, areas, latencies, and durations of the sequentially evoked motor unit potentials were obtained by a computer subtraction method (Ballantyne and Hansen, 1974b). In all patients the shortest distal motor latencies (SDML) and the fastest motor nerve conduction velocities (FMNCV) were measured in the lateral popliteal nerves, the supramaximally evoked muscle action potential from the EDB muscle being recorded from the undisturbed surface electrodes used in the estimation of motor unit numbers. All the investigations were carried out in a thermostatically controlled room and the limb temperature was maintained at $32^{\circ} \mathrm{C} \pm 1^{\circ} \mathrm{C}$.

\section{PATIENTS}

Seventeen patients aged between 19 and 70 years (mean 40.7 years) were studied, of whom seven were male and 10 female. The diagnosis was established on the basis of the clinical features, CSF examination, and lack of additional pathology known to produce polyneuropathy. Patients with a relapsing course were excluded from the study.

The clinical and CSF profiles of the patients at the time of diagnosis are listed in Table 1 and categorised after Ravn (1967). Two patients were in category 1a of Ravn (paresis of cranial and spinal nerves and 
Table 1 Symptoms and signs ai peak of illness

\begin{tabular}{|c|c|c|c|c|c|c|c|c|c|c|c|c|c|c|c|c|}
\hline \multirow{2}{*}{ No. } & \multirow{2}{*}{$\begin{array}{l}\vec{\vdots} \\
0 \\
0 \\
0\end{array}$} & \multirow{2}{*}{ Sex } & \multirow{2}{*}{$\begin{array}{l}A g ? \\
(y r)\end{array}$} & \multicolumn{3}{|c|}{ Cranial nerves } & \multicolumn{2}{|c|}{ Power loss } & \multicolumn{2}{|c|}{$\begin{array}{l}\text { Reflex } \\
\text { changes }\end{array}$} & \multirow{2}{*}{ ڤे } & \multirow{2}{*}{ Pain } & \multirow{2}{*}{ 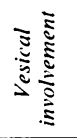 } & \multirow{2}{*}{ 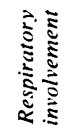 } & \multicolumn{2}{|l|}{$C S F$} \\
\hline & & & & $\begin{array}{l}3.4 \\
5.6\end{array}$ & 7 & $9-12$ & $U L$ & $L L$ & $U L$ & $L L$ & & & & & $\begin{array}{l}\text { Protein } \\
\left(g_{/} / l\right)\end{array}$ & $\begin{array}{l}\text { Cells } \\
\text { (lc.mm) }\end{array}$ \\
\hline 1 & \multirow[t]{5}{*}{ Ia } & $\mathbf{M}$ & 20 & & + & + & $++t$ & +++ & $\mathbf{A}$ & $\mathbf{A}$ & \pm & & - & $++t$ & 1.2 & $<5$ \\
\hline 2 & & $\mathrm{~F}$ & 38 & $+t+$ & $+t+$ & $++t$ & $+t+$ & $+t+$ & $\mathbf{A}$ & $\mathbf{A}$ & & - & + & +++ & * & $*$ \\
\hline 3 & & $\mathbf{M}$ & 70 & & ++ & - & \pm & $+t$ & $N$ & A & & - & - & - & 1 & $<5$ \\
\hline 4 & & $\mathbf{M}$ & 31 & & ++ & & ++ & +++ & A & A & : & - & ++ & & 0.6 & $<5$ \\
\hline 5 & & $\mathbf{F}$ & 29 & & + & $\cdots$ & + & + & $N$ & $\mathrm{H}$ & $\because$ & + & \pm & & $*$ & $*$ \\
\hline \multirow{2}{*}{6} & \multirow{5}{*}{$\mathrm{Ib}$} & & & \multirow[b]{2}{*}{++} & \multirow[b]{2}{*}{++} & \multirow[b]{2}{*}{-} & \multirow[b]{2}{*}{++} & \multirow[b]{2}{*}{+++} & \multirow[b]{2}{*}{ A } & \multirow[b]{2}{*}{ A } & \multirow[b]{2}{*}{$\therefore$} & \multirow[b]{2}{*}{++} & \multirow[b]{2}{*}{++} & \multirow[b]{2}{*}{ 一 } & 0.7 & 21 \\
\hline & & $F$ & 58 & & & & & & & & & & & & 1.3 & $<5$ \\
\hline 7 & & $F$ & 20 & & ++ & - & - & + & A & A & ++ & - & - & & $*$ & $*$ \\
\hline 8 & & $F$ & 29 & & : & -- & + & ++ & $\mathrm{H}$ & A & ++ & ++ & $\therefore$ & & 0.95 & 170 \\
\hline 9 & & $\mathbf{F}$ & 47 & & : & & + & ++ & $\mathbf{H}$ & A & ++ & + & $\cdots$ & - & 1.3 & 2 \\
\hline 10 & \multirow{3}{*}{ Ila } & $\mathbf{M}$ & 61 & & - & - & +++ & $++t$ & A & A & $!$ & & - & +++ & 0.5 & $<5$ \\
\hline 11 & & $F$ & 59 & & - & - & ++ & +++ & A & A & $\therefore$ & $=$ & - & $\therefore$ & 2.05 & $<5$ \\
\hline 12 & & $F$ & 38 & & $\cdots-$ & -- & ++ & +++ & A & A & $:$ & - & $\cdots$ & & 0.55 & $<1$ \\
\hline 13 & $\mathrm{Ilb}$ & $\mathbf{F}$ & 40 & - & - & - & $+t+$ & +++ & A & $\mathbf{A}$ & ++ & $++t$ & - & + & $\begin{array}{l}1.8 \\
2.56\end{array}$ & $\begin{array}{l}7 \\
<5\end{array}$ \\
\hline \multirow[t]{2}{*}{14} & & $\mathbf{F}$ & 19 & & - & - & ++ & ++ & $\mathbf{H}$ & A & & - & - & - & -1 & 20 \\
\hline & & & & & & & & & & & & & & & $\begin{array}{l}3.4 \\
1.35\end{array}$ & $\begin{array}{l}30 \\
<5\end{array}$ \\
\hline 15 & & $\mathbf{M}$ & 43 & - & - & - & - & t. & $N$ & A & ! & $\because$ & - & $\cdots$ & 0.55 & $<5$ \\
\hline 16 & & $\mathbf{M}$ & 55 & & . & & & ++ & $\mathbf{N}$ & A & + & & ++ & - & 0.43 & $<5$ \\
\hline 17 & & $\mathbf{M}$ & 35 & & & & - & ++ & $N$ & A & + & + & - & - & 2.4 & 2 \\
\hline
\end{tabular}

UL Upper limbs. LL Lower limbs. +++ Very severe involvement. ++ Severe involvement. + Moderate involvement. + Mild involvement.

- No involvement. N Normal reflexes. A Areflexia. H Hyporeflexia. * Lumbar puncture not performed.

severe respiratory involvement). Seven patients were included in category $1 \mathrm{~b}$ (paresis of cranial and spinal nerves and mild or absent respiratory involvement). One patient was in category $2 \mathrm{a}$ (tetraplegia and severe respiratory involvement). Four patients were in category $2 b$ (tetraplegia and mild or absent respiratory involvement), and three patients in category $3 \mathrm{~b}$ (paraparesis). None were in categories $3 a, 4$, or 5 of Ravn. All patients fulfilled the diagnostic criterid of Massucci and Kurtzke (1971):

1. The syndrome was not secondary to any other disorder known to cause neuropathy.

2. The onset was acute in 13 of the patients and subacute in the remainder. A history of antecedent illness was obtained in eight of the patients; upper respiratory tract infection in four patients, urinary tract infection in two, and gastrointestinal symptoms in two patients.

3. The most common initial symptoms were sensory in type consisting of pain in various parts of the body and or numbness and paraesthesia in the limbs. These symptoms occurred in 12 of the 17 patients. In one patient sensory symptoms were associated with increased frequency and urgency of micturition. Weakness of the lower limbs was the first symptom in three patients. Dysarthria and sensory ataxia occurred at the onset in one patient.

4. Symptoms and signs ascended in 10 patients, ascended and descended in two, and remained confined to the extremities in five.

5. Motor involvement was both proximal and distal in 10 of the patients and distal only in seven.

6. At the peak of the illness motor involvement predominated. In seven cases both motor and sensory signs were present. In seven there were motor signs but only subjective sensory disturbances and in three cases no disturbance of sensation was reported.

7. Changes in tendon reflexes occurred in all our patients and ranged from hyporeflexia in the lower limbs only to generalised areflexia.

8. The cranial nerves were affected in nine patients, the facial nerve being involved in all of these. In addition, the sixth cranial nerve was affected bilaterally in one patient, in others both the ninth and tenth cranial nerves were involved, and in another the ninth, 10th, 11 th, and 12 th nerves were affected.

9. The CSF protein was raised above $0.5 \mathrm{~g} / \mathrm{l}$ in 12 patients. In three patients CSF examination was not carried out. In only three patients was there a moderate increase in the number of nucleated cells in the CSF.

10. Clinical improvement occurred in all 16 patients who survived the acute phase of the illness (one of the patients died after a cardiac arrest during the illness) but showed considerable variability.

11. Miscellaneous features during the acute phase 
included urinary incontinence in three cases and dysuria in two others. One patient had extensor plantar responses, and another developed an acute but transient confusional state.

The time from the onset of the acute phase of the illness to the present study varied from five days to 9.5 years with a mean of 2.8 years. In five patients two electrophysiological studies were performed, the first during the acute phase of the illness and the second several months later and during the recovery phase. At the time of the present studies the patients were re-examined for evidence of clinical disability. Of the 16 survivors only two showed a complete clinical recovery (Table 2 ).

\section{Results (Tables 2, 3, and 4)}

SHORTEST DISTAL MOTOR LATENCIES (SDML)

The mean SDML was significantly prolonged in acute idiopathic polyneuritis. The SDML was in the normal range in five of the patients, although in one of them (case 10) it was prolonged in the first study performed one month after the onset of the illness, but more than one year before the second examination.

\section{FASTEST MOTOR NERVE CONDUCTION VELOCITY} (FMNCV)

In three of the patients the FMNCV was normal but in the group as a whole the mean FMNCV was significantly reduced. In one of the five patients on whom two studies were undertaken the FMNCV showed an improvement between the first and second studies (case 10). There is a negative correlation between the FMNCV and the SDML $(r=-0.646$; $P<0.002)$.

\section{MOTOR UNIT NUMBERS}

The number of motor units in the EDB muscle was significantly reduced in the group as a whole, but was normal in four patients. Motor unit numbers increased with the passage of time from the acute illness. There is a negative correlation between motor unit numbers and the degree of clinical disability at the time of the estimation $(r=-0.494 ; \mathrm{P}<0.05)$.

\section{LATENCY OF MOTOR UNIT POTENTIALS}

The mean latency of the motor unit potentials (MUP) was significantly prolonged. There is a positive correlation between the mean MUP latency and the

Table 2 Clinical features at time of neurophysiological examination

\begin{tabular}{|c|c|c|c|c|c|c|c|c|c|}
\hline \multirow[t]{3}{*}{ No. } & \multirow{3}{*}{$\begin{array}{l}\text { Time from } \\
\text { onset to } \\
\text { present tests } \\
(y r)\end{array}$} & \multicolumn{5}{|c|}{ Present disability } & \multicolumn{3}{|l|}{ Results } \\
\hline & & \multirow{2}{*}{$\begin{array}{l}\text { Cranial } \\
\text { nerves }\end{array}$} & \multicolumn{3}{|c|}{ Motor involvement } & \multirow{2}{*}{$\begin{array}{l}\text { Sensory } \\
\text { Loss }\end{array}$} & \multirow{2}{*}{$\begin{array}{l}\text { Motor } \\
\text { unit } \\
\text { numbers }\end{array}$} & \multirow{2}{*}{$\begin{array}{l}S D M L \\
(m s)\end{array}$} & \multirow{2}{*}{$\begin{array}{l}\text { FMNCV } \\
(\mathrm{m} / \mathrm{s})\end{array}$} \\
\hline & & & $\overline{U L}$ & $L L$ & Reflexes & & & & \\
\hline 1 & 2 & - & - & - & - & - & 34 & 8.0 & 38 \\
\hline 2 & lw & $++t$ & +++ & +++ & +++ & _- & 9 & 7.2 & 46 \\
\hline \multirow[t]{2}{*}{3} & 1 & - & \pm & + & $\begin{array}{r}T T \\
\pm\end{array}$ & \pm & 95 & 5.3 & $\begin{array}{l}40 \\
37\end{array}$ \\
\hline & $8 w$ & ++ & $++\overline{+}$ & +++ & +++ & \pm & 7 & 20.0 & 28 \\
\hline \multirow{2}{*}{4} & $6 \mathrm{~m}$ & - & + & ++ & +++ & \pm & 0 & $*$ & 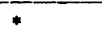 \\
\hline & $1 \mathrm{~m}$ & \pm & + & + & & \pm & 27 & 5.0 & 43 \\
\hline 5 & $2 \frac{1}{2}$ & $\ldots$ & - & $\ldots$ & \pm & \pm & 8 & 4.5 & 54 \\
\hline \multirow[t]{2}{*}{6} & 2 & ++ & - & + & \pm & $=$ & 147 & 4.6 & 47 \\
\hline & $1 \mathrm{~m}$ & ++ & - & + & ++ & \pm & 99 & 14.0 & 27 \\
\hline 7 & $3 m$ & + & - & \pm & + & \pm & 71 & 7.5 & 36 \\
\hline 8 & 7 & - & - & \pm & + & \pm & 74 & 3.2 & 52 \\
\hline \multirow[t]{2}{*}{9} & 13d & \pm & + & ++ & ++ & ++ & 16 & 4.3 & * \\
\hline & $1 \mathrm{~m}$ & \pm & +++ & +++ & $++t$ & \pm & 33 & 5.7 & 31 \\
\hline 10 & $1 \frac{1}{2}$ & $\ldots$ & - & - & + & - & 71 & 3.5 & 46 \\
\hline \multirow[t]{2}{*}{11} & $2 \frac{1}{2}$ & -- & $\ldots$ & - & + & + & 77 & 5.4 & 44 \\
\hline & $\begin{array}{l}22 \\
6 w\end{array}$ & - & ++ & +++ & ++ & \pm & 39 & 3.7 & 44 \\
\hline 12 & $6 \mathrm{~m}$ & - & $t$ & + & + & \pm & 166 & 4.0 & 42 \\
\hline 13 & 91 & - & -2 & - & - & \pm & 212 & 3.4 & 46 \\
\hline 14 & 8 & - & - & \pm & $\frac{1}{1:}$ & - & $*$ & 8.3 & 27 \\
\hline 15 & 21 & - & -. & $=$ & - & - & 135 & 5.2 & 35 \\
\hline 16 & 3 & - & - & \pm & - & \pm & 88 & 6.2 & 46 \\
\hline 17 & $2 \frac{1}{2}$ & - & - & 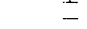 & - & \pm & 56 & 7.2 & 47 \\
\hline
\end{tabular}

+++ Very severe involvement. ++ Severe involvement. + Moderate involvement \pm Mild involvement. - No involvement. UL Upper limbs. LL Lower limbs. * No result available. 
Table 3 Mean age, SDML, FMNCV, and motor unit number

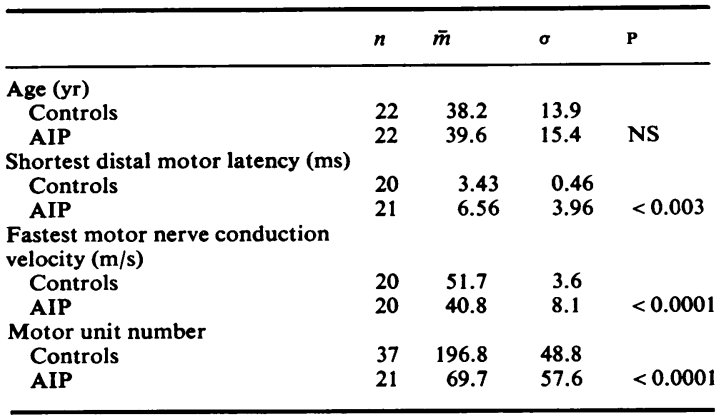

Table 4 Mean MUP parameters in EDB muscle

\begin{tabular}{lllll}
\hline & $n$ & $\bar{m}$ & $\sigma$ & $P$ \\
\hline $\begin{array}{l}\text { Latency of motor unit potentials } \\
\text { (ms) }\end{array}$ & 160 & 4.49 & 0.82 & \\
$\quad \begin{array}{l}\text { Controls } \\
\text { AIP }\end{array}$ & 117 & 7.38 & 5.00 & $<0.0001$ \\
$\begin{array}{l}\text { Duration of motor unit potentials } \\
\text { (ms) }\end{array}$ & 160 & 9.5 & 1.7 & \\
$\quad \begin{array}{l}\text { Controls } \\
\quad \text { AIP }\end{array}$ & 117 & 11.57 & 3.61 & $<0.0001$ \\
$\begin{array}{l}\text { Amplitude of motor unit } \\
\text { potentials }(\mu \mathrm{V})\end{array}$ & & & & \\
$\quad \begin{array}{l}\text { Controls } \\
\quad \text { AIP }\end{array}$ & 160 & 58.6 & 28.5 & \\
$\begin{array}{l}\text { Area of motor unit potentials } \\
\text { (Units of Area) }\end{array}$ & 117 & 77.3 & 78.0 & $<0.02$ \\
$\quad \begin{array}{lllll}\text { Controls } \\
\text { AIP }\end{array}$ & 160 & 16.5 & 7.6 & \\
\hline
\end{tabular}

SDML $(r=0.98 ; \mathrm{P}<0.001)$ and a negative correlation with the FMNCV $(r=-0.744 ; \mathrm{P}<0.001)$.

DURATION OF MOTOR UNIT POTENTIALS

The mean duration of MUPs was significantly prolonged. There is a positive correlation between the mean MUP duration and the SDML in each patient $(r=0.762 ; \mathrm{P}<0.001)$ and a negative correlation with the fastest motor nerve conduction velocity $(r=-0.538 ; \mathrm{P}<0.05)$.

AMPLITUDE OF MOTOR UNIT POTENTIALS

The mean amplitude was significantly increased. There is a positive correlation of this parameter with the FMNCV $(r=0.538 ; \mathrm{P}<0.05)$.

\section{AREA OF MOTOR UNIT POTENTIALS}

The mean area of motor unit potentials was significantly increased.

\section{Discussion}

We have found a reduction in the number of functioning motor units at the time of examination in patients with acute idiopathic polyneuritis (Table 2). The number of motor units slowly increased with the passage of time from the acute illness, but in only four of the 16 patients who survived were normal motor unit numbers found.

Pathological reports of cases of acute idiopathic polyneuritis in which necropsy or biopsy has been performed indicate that segmental demyelination is the prominent feature and has been considered to be the most important in determining the clinical disability during the acute phase of the illness (Haymaker and Kernohan, 1949; Asbury et al., 1969; Wisniewski et al., 1969; Carpenter, 1972; Prineas, 1972; McLeod et al., 1976).

Axonal damage has also been reported in pathological studies (Haymaker and Kernohan, 1949; Asbury et al., 1969; Carpenter, 1972; Prineas, 1972; McLeod et al., 1976) and in some studies it has been particularly frequent as in the 19 cases reported by Asbury et al. (1969) where Wallerian degeneration and associated chromatolysis of anterior horn cells and in some cases complete dissolution of the anterior horn cells was noted.

Damage to the axon or to the anterior horn cells will, if sufficiently severe, produce a decrease in the number of functioning motor units. The reduction in motor unit numbers may be reversible or permanent depending on the severity and reversibility of the axonal and/or anterior horn cell damage and/or the distance over which regenerating axons must grow to reinnervate muscle fibres. It is known that the latter are no longer available for reinnervation after a period of $1 \frac{1}{2}$ to three years (Bowden and Guttmann, 1944; Guttmann and Young, 1944; Guttmann, 1948; Oppenheimer and Spalding, 1973). There are probably two simultaneous pathological processes, demyelination and axonal degeneration, occurring in acute idiopathic polyneuritis at the time of the fully developed illness, the former usually more intense and to some extent obscuring the effect of the latter which manifests itself after the resolution of the demyelinating process. Whether axonal degeneration is a primary or secondary event is not known but it appears unlikely that anterior horn cell dissolution can be accounted for on the basis of primary demyelination of the peripheral nerve and therefore is of itself a primary event. This would be supported by the study of Bradley and Jennekens in 1971 in their investigation of axonal damage in experimental diphtheritic neuropathy. Complete block to conduction of the nerve impulses is known to occur in experimentally induced demyelinating peripheral neuropathy (Cragg and Thomas, 1964) but these authors noted that this event occurred infrequently and that the predominant electrophysiological manifestation of demyelination was reduction of con- 
duction velocity of the action potential across the affected segments. Rosenfalck and Buchthal (1970) found electrophysiological changes compatible with demyelination without block in mild cases of polyneuropathies including acute idiopathic polyneuritis. But complete conduction block did occur in more severely involved patients. The possibility therefore must be considered that loss of function in some motor units may be due to complete block to transmission from demyelination without significant axon dysfunction. This hypothesis is not, however, compatible with the present electrophysiological results. The increase in motor unit numbers with time from the onset of the illness is a slow process and is in a majority of patients incomplete even after two to three years. This sequence of events is more suggestive of the slower process of axonal degeneration. Furthermore segmental demyelination is not associated with anatomical denervation of muscle fibres and fibrillation is not found when the axon retains its connections with the muscle (Adams et al., 1962; Robert and Oester, 1970). The significant increase in the area and amplitude of motor unit potentials noted in this study is due to an increase in the muscle fibre content of functioning motor units, presumably by a process of collateral reinnervation of muscle fibres which have lost their primary innervation. The latter must be considered as evidence of the presence of significant axonal regeneration in these patients. Partial recovery from acute idiopathic polyneuritis is usually found some weeks or months after the acute illness, followed by a further slow improvement over a few years. It appears to us that the relatively early and rapid recovery of function that occurs in the majority of patients is secondary to remyelination, improvement of conduction, and unblocking of conduction in some motor fibres. The further slow, often incomplete, improvement in electrophysiological parameters is a consequence of axonal regeneration and collateral reinnervation. The efficiency of collateral reinnervation in contributing to the return of muscle power is illustrated by those patients who have reduced motor unit numbers without clinical motor disability. In these patients the MUP are of increased dimensions. These changes were found in six of the nine patients examined more than two years after the onset of the illness. In the group as a whole, motor unit counts do, however, correlate with the degree of clinical disability, so that collateral reinnervation does not entirely compensate for loss of motor units.

Prolongation of the latencies of individual motor unit potentials is due to slowing of conduction through the fine intramuscular nerve fibres of the motor axon as discussed previously (Ballantyne and Hansen, 1975). This produces not only prolongation of the latencies of the individual motor unit potentials but also of their durations (Ballantyne and Hansen, $1975)$ and there is a positive correlation between them $(r=0.786, \mathrm{P}<0.001)$. The mean amplitude and mean area of the motor unit potentials were significantly increased in our cases. These results indicate the presence of collateral reinnervation with a consequent increase in the number of muscle fibres in the remaining motor units, as already described. Thirteen of the 17 patients had prolongation of the shortest distal motor latencies outside the range of control subjects, while only eight patients had a reduction in the fastest motor nerve conduction velocities below normal values, suggesting that the electrophysiological abnormality was more severe in the intramuscular nerve fibres than in the parent motor axons.

In only four of the 10 patients examined later than two years after the onset of the illness was complete recovery found and in only one of these 10 patients were completely normal electrophysiological parameters obtained in this study.

\section{Conclusions}

Our results indicate that, in the majority of patients? with acute idiopathic polyneuritis, significant axo용 dysfunction is present which manifests itself electro? 윽 physiologically by a persistent reduction in the moto $\$$ unit numbers and a compensatory increase in the size T of surviving motor units, presumably by a process of 을 collateral reinnervation.

The early and rapid phase of clinical recovery can be attributed to remyelination but the slower an delayed improvement which appears to continue for several years after the onset of the illness is accompanied by electrophysiological evidence of axonal regeneration-namely, a slow increase in the number of motor units and an increase in the dimensions of these units. In our studies the electrophysiological abnormalities were more marked in the intramuscular nerve fibres than in the parent axons, with prolongation of the shortest distal motor latencies and the latencies of single motor unit potentials with secondary changes in the duration of the motor unit potentials.

Complete electrophysiological recovery in this study was found in only one of 10 patients examined more than two years after the onset of the illness despite the presence of full recovery of motor power on clinical examination.

We would like to thank Professor J. A. Simpson for his help and encouragement and Mrs C. FraserCampbell for secretarial assistance. This investigation was supported by grants from the Muscular Dystrophy Group of Great Britain (A.M-F.) and the Wellcome Trust (S.H.). 


\section{References}

Adams, R. D., Denny-Brown, D., and Pearson, C. M. (1962). Diseases of Muscle. A Study in Pathology, 2nd edn. Harper: New York.

Asbury, A. K., Arnason, B. G., and Adams, R. D. (1969). The inflammatory lesion in idiopathic polyneuritis. Its role in pathogenesis. Medicine (Balt.), 48, 173-215.

Ballantyne, J. P., and Hansen, S. (1974a). A new method for the estimation of the number of motor units in a muscle. 1. Control subjects and patients with myasthenia gravis. Journal of Neurology, Neurosurgery, and Psychiatry, 37, 907-915.

Ballantyne, J. P., and Hansen, S. (1974b). Computer method for the analysis of evoked motor unit potentials. 1. Control subjects and patients with myasthenia gravis. Journal of Neurology, Neurosurgery, and Psychiatry, 37, 1187-1194.

Ballantyne, J. P., and Hansen, S. (1975). Computer method for the analysis of evoked motor unit potentials. 2 . Duchenne, limb-girdle, facioscapulohumeral and myotonic muscular dystrophies. Journal of Neurology, Neurosurgery, and Psychiatry, 38, 417-428.

Bannister, R. G., and Sears, T. A. (1962). The changes in nerve conduction in acute idiopathic polyneuritis. Journal of Neurology, Neurosurgery, and Psychiatry, 25, 321-328.

Bergamini, L. G., Gandiglio, G., and Fra, L. (1966). Motor and afferent nerve conduction in the GuillainBarré-Strohl syndrome. A longitudinal study in 5 cases with different clinical features. Electromyography (Louvain), 6, 205-232.

Bowden, R. E. M., and Guttmann, E. (1944). Denervation and re-innervation of human voluntary muscle. Brain, 67, 273-313.

Bradley, W. G., and Jennekens, F. G. I. (1971). Axonal degeneration in diphtheritic neuropathy. Journal of the Neurological Sciences, 13, 415-430.

Carpenter, S. (1972). An ultrastructural study of an acute fatal case of the Guillain-Barré syndrome. Journal of the Neurological Sciences, 15, 125-140.

Cragg, B. G., and Thomas, P. K. (1964). Changes in nerve conduction in experimental allergic neuritis. Journal of Neurology, Neurosurgery, and Psychiatry, 27, 106-115.

Guttmann, E. (1948). Effect of delay of innervation on recovery of muscle after nerve lesions. Journal of Neurophysiology, 11, 279-294.

Guttmann, E., and Young, J. Z. (1944). Re-innervation of muscle after various periods of atrophy. Journal of Anatomy, 78, 15-43.

Haymaker, W., and Kernohan, J. W. (1949). The LandryGuillain-Barré syndrome: A clinicopathologic report of fifty fatal cases and a critique of the literature. Medicine (Balt.), 28, 59-141.

Humphrey, J. G. (1964). Motor nerve conduction studies in the Landry-Guillain-Barré syndrome (acute ascending polyneuropathy). Electroencephalography and Clinical Neurophysiology, 17,96.
Isch, F., Isch-Treussard, C., Buchheit, F., Delgado, V., and Kircher, J. P. (1964). Measurement of conduction velocity of motor nerve fibres in polyneuritis and polyradiculoneuritis. Electroencephalography and Clinical Neurophysiology, 16, 416.

Kimura, L., and Butzer, J. F. (1975). F wave conduction velocity in Guillain-Barré syndrome. Archives of Neurology (Chic.), 32, 524-529.

Lambert, E. H., and Mulder, D. W. (1964). Nerve conduction in the Guillain-Barré syndrome. Electroencephalography and Clinical Neurophysiology, 17, 86.

McComas, A. J., Fawcett, P. R. W., Campbell, M. J., and Sica, R. E. P. (1971). Electrophysiological estimation of the number of motor units within a human muscle. Journal of Neurology, Neurosurgery, and Psychiatry, 34, 121-131.

McLeod, J. G., Walsh, J. C., Prineas, J. W., and Pollard, J. F. (1976). Acute idiopathic polyneuritis. A clinical and electrophysiological follow-up study. Journal of the Neurological Sciences, 27, 145-162.

McQuillen, M. P. (1971). Idiopathic polyneuritis. Serial studies of nerve and immune functions. Journal of Neurology, Neurosurgery, and Psychiatry, 34, 607-615.

Massucci, E. F., and Kurtzke, J. F. (1971). Diagnostic criteria for the Guillain-Barré syndrome. Journal of the Neurological Sciences, 13, 483-501.

Oppenheimer, D. R., and Spalding, J. M. K. (1973). Late residua of acute idiopathic polyneuritis. Journal of Neurology, Neurosurgery, and Psychiatry, 36, 978-988.

Peterman, A. F., Daly, D. D., Dion, F. R., and Keith, H. M. (1959). Infectious neuritis (Guillain-Barré syndrome) in children. Neurology (Minneap.), 9, 533-539.

Prineas, J. W. (1972). Acute idiopathic polyneuritis. An electron microscopic study. Laboratory Investigation, 26, 133-147.

Raman, P. T., and Taori, G. M. (1976). Prognostic significance of electro-diagnostic studies in the GuillainBarré syndrome. Journal of Neurology, Neurosurgery, and Psychiatry, 39, 163-170.

Ravn, H. (1967). The Landry-Guillain-Barré syndrome. Acta Neurologica Scandinavica, suppl. 30, 43, 1-64.

Robert, E. D., and Oester, Y. T. (1970). Nerve impulses and trophic effect. Absence of fibrillation after prolonged and reversible conduction block. Archives of Neurology (Chic.), 22, 57-63.

Rosenfalck, A., and Buchthal, F. (1970). Demyelination and axonal degeneration. Acta Neurologica Scandinavica, suppl. 43, 46, 199.

Sigwald, J., and Nouailhat, F. (1970). The GuillainBarré syndrome. In Handbook of Clinical Neurology, vol. 7, pp. 502-506. Edited by P. J. Vinken, and G. W. Bruyn. North Holland: Amsterdam.

Wisniewski, H. R. D., Terry, J. N., Whitaker, S. D., Cook, S. D., and Dowling, P. C. (1969). LandryGuillain-Barré syndrome. A primary demyelinating disease. Archives of Neurology (Chic.), 21, 269-276. 